\title{
Shaking table test on seismic response of reduced-scale models of multi-story buildings allowed to uplift
}

\author{
T. Ishihara ${ }^{1}$, T. Azuhata ${ }^{1}, \mathrm{~K}$. Noguchi $^{1}, \mathrm{~K}$. Morita $^{2}$ \\ \& M. Midorikawa ${ }^{3}$ \\ ${ }^{I}$ National Institute for Land and Infrastructure Management, Japan \\ ${ }^{2}$ Building Research Institute, Japan \\ ${ }^{3}$ Hokkaido University, Japan
}

\begin{abstract}
The effects of rocking vibration accompanied by uplift motion may reduce seismic damage to buildings. Structural systems that are allowed to uplift can be recognized as one of the simplest "self-centring" systems utilizing potential energy of self-weight. To investigate the effect of uplift motion on seismic responses of buildings experimentally, we conducted parametric shaking table tests using reduced-scale specimens with multi-stories. In this paper, the results of the tests are reported and discussed.
\end{abstract}

Keywords: self-centering, seismic response reduction, rocking vibration, reduced-scale model, higher mode.

\section{Introduction}

It has been pointed out that structural systems of buildings during strong earthquakes have been subjected to foundation uplift $[1,2]$. After the first study by Muto et al. [3], many studies dealing with foundation uplift in flexible systems have been conducted (e.g. [4-7]) and some of these researches are summarized in the appendix of ATC-40 [8]. The authors also studied experimentally and analytically from the point of view of utilizing transient uplift motion for reduction of seismic response (e.g. [9-11]). In the experiment, 5 story and 3 story reduced scale steel frame were used as specimen.

Structural system allowed to uplift can be recognized as one of the simplest "self-centring" system. This system utilizes potential energy of self-weight to 
absorb the seismic input energy temporally. Because the reduction of seismic forces makes the structure easy to remain in its elastic range, no residual deformation may be caused in this system after an earthquake.

As pointed out in the literature, structures allowed to uplift have nonlinear behaviour and are subjected to impact forces after an excursion of an uplift motion, more experimental data should be needed to utilize transient uplift motion for seismic design of buildings to survive the severe earthquake without residual deformation.

Now we planed parametric shaking table tests with small scale models. Experimental parameters of the models can be natural period, number of stories, stiffness distribution along the height, etc. In this paper, part of the experimental results are reported and discussed.

\section{Specimen and experimental procedures}

\subsection{Specimen}

Figure 1 shows the specimen. The specimen is composed of units bolted each other in vertical direction. Each unit corresponds to each story of shear-type buildings with one bay. The height and span of the units are $218 \mathrm{~mm}$ and $200 \mathrm{~mm}$ respectively. The weight of the units is only about $17 \mathrm{~kg}$, light enough to handle by oneself. Each unit has two floor elements (steel plates, $\mathrm{t}=9 \mathrm{~mm}$ ) at its top and bottom. To make the natural period of the specimen enough to long to represent the dynamic behaviours of real buildings and to provide sufficient vertical stiffness and strength to sustain impact force at landing after an uplift motion, vertical resisting elements (VREs) and horizontal resisting elements (HREs) are arranged separately. As VREs and HREs, four steel flat bars (50x6) with butt hinges at both ends and four piano wires $\left(D=4 \mathrm{~mm}, \sigma y(0.2 \%\right.$ offset $\left.)=1.2 \mathrm{kN} / \mathrm{mm}^{2}\right)$ are used respectively. Each unit is recognized as a one-directional link with elastic HREs.

To allow the specimen to uplift, pins with half cylindrical shape $(R=20 \mathrm{~mm})$ are attached on the bottom plate of the lowest unit. Supports with a shallow Vshaped channel are attached on the footing beam as in the preceding test [9]. The specimen is just put on the supports, so the specimen is allowed to uplift without slippage between the specimen and the footing beam under earthquake excitation.

For fixed base condition, the bottom plate of the lowest unit is tightly bolted to the footing beam.

Table 1 shows the model properties. In this paper, the results of 3 models with 4,6 , and 8 stories are reported. The stiffness distribution along the height is uniform. Natural periods of models are as long as those of real buildings. In the table, "critical" means the initiation level of uplift, that is, the level when the overturning moment reaches the resisting moment due to self-weight. "Normalized overturning moment" means that the overturning moment is normalized by $M g B / 2$, where $M$ is total mass of the specimen, $g$ is gravitational acceleration and $B$ is span $(B=200 \mathrm{~mm})$. 


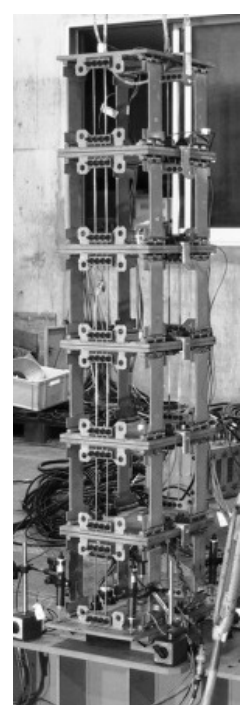

(a) Overview(U6)

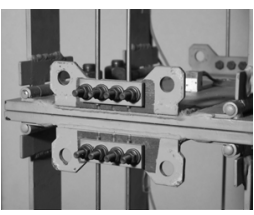

(b) Piano wires and its connection

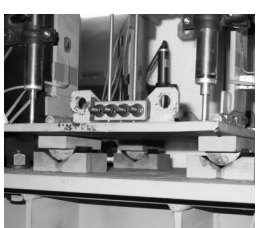

(c) Base

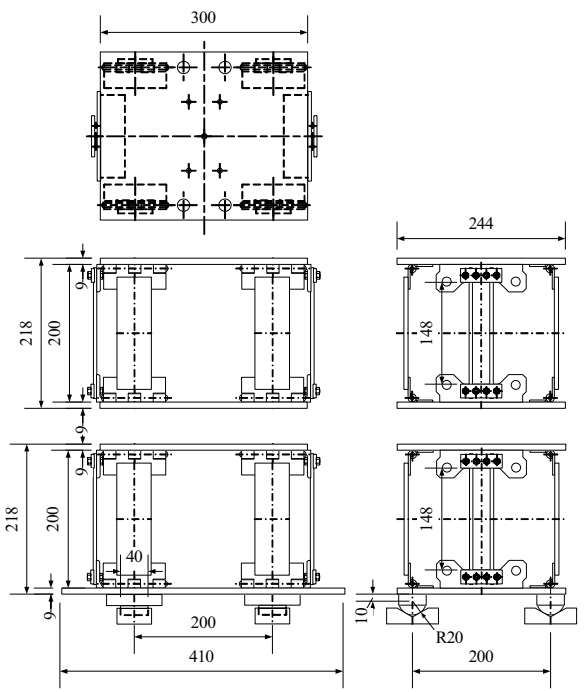

(d) Units (Lower: the lowest)

Figure 1: Reduced scale model.

Table 1: $\quad$ Model properties.

\begin{tabular}{|c|c|c|c|c|c|c|}
\hline Model & $\begin{array}{c}\text { Number } \\
\text { of } \\
\text { stories }\end{array}$ & H/B & Period(s)* & $\begin{array}{c}\text { Damping } \\
\text { ratio } \\
(\%)^{*}\end{array}$ & $\begin{array}{c}\text { Critical } \\
\text { base shear } \\
\text { coefficient } \\
* *\end{array}$ & $\begin{array}{c}\text { Critical } \\
\text { normalized } \\
\text { overturning } \\
\text { moment** }\end{array}$ \\
\hline U4 & 4 & 4.41 & 0.35 & 9.9 & 0.198 & 0.950 \\
\hline U6 & 6 & 6.59 & 0.60 & 5.4 & 0.120 & 0.906 \\
\hline U8 & 8 & 8.77 & 0.88 & 4.6 & 0.083 & 0.853 \\
\hline
\end{tabular}

* based on the results of free vibration tests under fixed base condition

** 1st mode approximation considering $\mathrm{P} \Delta$ effect

\subsection{Experimental procedure}

The specimen is oscillated only in one horizontal direction. Earthquake excitation used in the shaking table test is $1940 \mathrm{El}$ Centro NS component. The time scale is not changed but the input amplitude (I.A.) is selected at a wide range of intensities. Figure 2 shows pseudo velocity spectrum based on the acceleration measured on the shaking table.

The measured structural response quantities were all horizontal floor acceleration (more precisely, acceleration parallel to floors), all horizontal floor displacement, uplift displacement, vertical acceleration (more precisely, acceleration parallel to VREs) in the lowest story. 


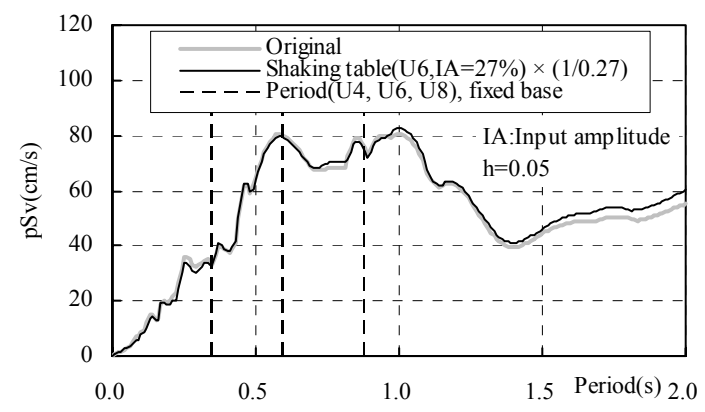

Figure 2: $\quad$ Pseudo velocity spectrum.

\section{Test results and discussion}

\subsection{Calculation of responses}

Before the results are shown, the methods of calculation of responses are explained. When the rotation $\theta$ of the base becomes large due to uplift, measured acceleration parallel to floors, $a_{i}$, includes the components due to gravity and vertical response acceleration, $a_{v}$.

$$
a_{i}=\left(\ddot{u}_{i}+\ddot{y}_{g}\right) \cos \theta-\left(g+a_{v}\right) \sin \theta \approx \ddot{u}_{i}+\ddot{y}_{g}-\left(g+a_{v}\right) \theta
$$

where $\ddot{u}_{i}$ is relative horizontal acceleration, $\ddot{y}_{g}$ is base (shaking table) horizontal acceleration. $a_{v}$ is calculated by the measured acceleration parallel to the lowest unit's VREs considering its inclination. In equation (1), we assume that $\theta$ and $a_{v}$ are independent of the height of floor because the specimen is designed as shear type structure. The absolute horizontal accelerations of floors are,

$$
\ddot{u}_{i}+\ddot{y}_{g} \approx a_{i}+\left(g+a_{v}\right) \theta
$$

Story shears and story moments are computed based on the absolute horizontal accelerations calculated by the right-hand side of equation (2) and the masses measured in advance. Overturning moment is calculated as the sum of story moments.

Restoring moment $m_{B}$ due to self-weight considering the deformation of the specimen is as follows:

$$
\frac{m_{B}}{M g B / 2}=\mp 1+\sum\left(\frac{M_{i}}{M} \frac{u_{i}}{B / 2}\right)
$$

where $M_{i}$ is the mass of floor, $u_{i}$ is the relative horizontal displacement of floor. The second term on the right-hand side in equation (3) is negligible in real scale buildings, but it should be included in the small scale and flexible test as shown in this paper. 


\subsection{Dynamic behaviour and maximum responses}

Figure 3 shows the time histories of roof displacement, comparing those of fixed base condition under the same input amplitude. Although the displacements become larger than those of fixed base, elastic deformations of superstructures are smaller because almost over half of the displacements are caused by rigid rotation.

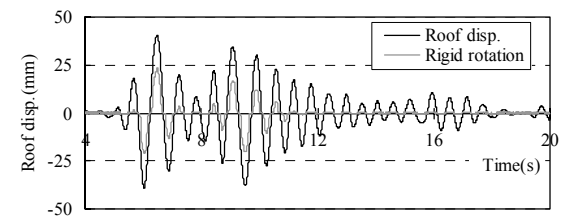

(a)

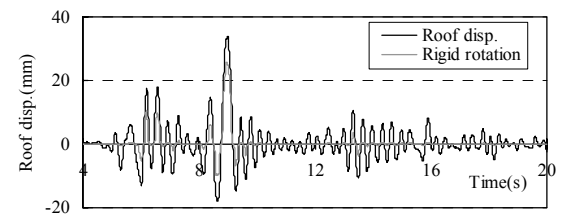

(c)

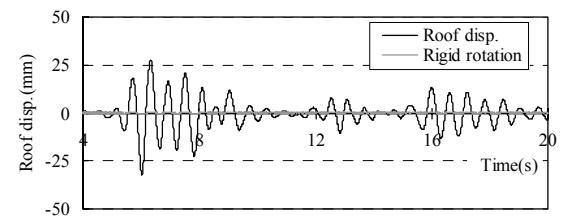

(b)

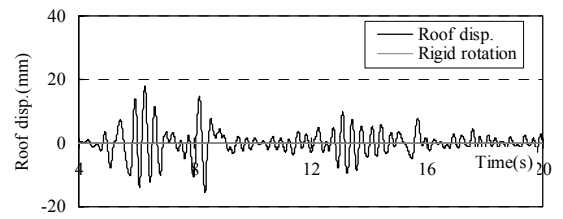

(d)

Figure 3: Time histories of roof horizontal displacement: (a) U6(I.A.=27.0\%); (b) U6fix(I.A.=27.0\%); (c) U4(I.A.=74.7\%); (d) U4fix(I.A. $=74.7 \%)$.

Figure 4 shows the time histories of absolute horizontal accelerations (see eq. (2)), story shear coefficients in the lowest (1st) stories (i.e. base shear coefficients), overturning moments and uplift displacements. Dot-dash lines and doted gray lines show the critical base shear coefficients (see table 1) and restoring moment due to self-weight (see eq. (3)) respectively. Once a transient uplift motion starts, shorter periodic vibrations are clearly observed. Those are relatively larger compared to fixed base condition. These phenomena are recognized to be higher mode effect as pointed out mainly by analytical studies (e.g. $[4,6,7,11])$.

Figure 5 shows dynamic load displacement relationships. Doted lines show stiffness of the first mode in fixed base condition based on the measured natural period of the model and critical base shear coefficient. Maximum forces are reached just after lift-off. During an excursion of transient uplift motion, higher mode effects can be also observed in these graphs.

Figure 6 shows maximum base shear and overturning moment comparing those of fixed base condition. Horizontal doted lines show critical values. The results show that allowing uplift reduces the seismic forces. 

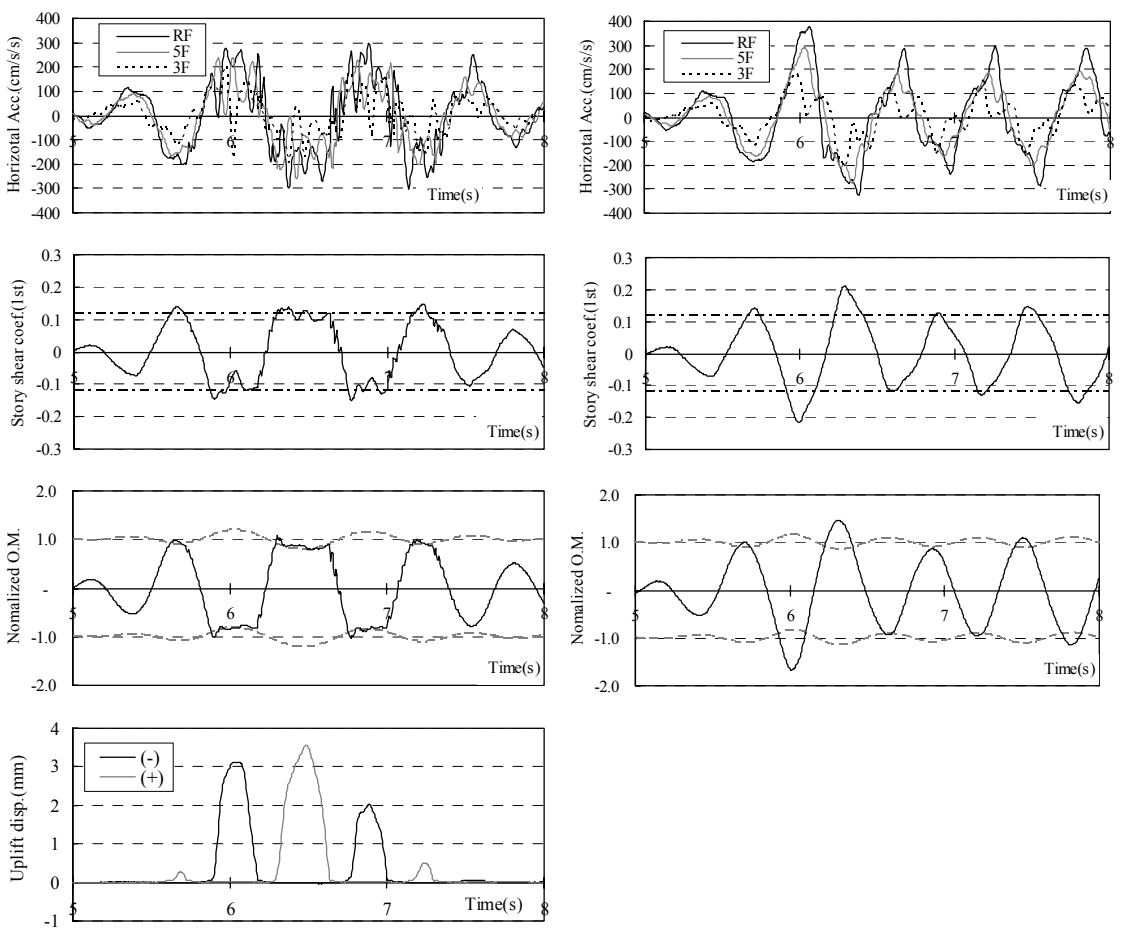

(a)

(b)

Figure 4: Time histories of responses, U6 (I.A.=27.0\%): (a) U6; (b) U6fix.
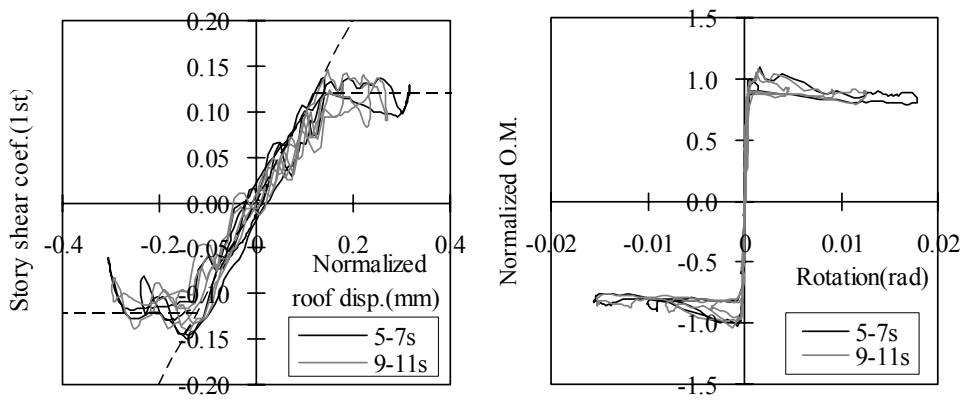

U6 (I.A. $=27.0 \%)$

Figure 5: Dynamic load displacement relationship. 

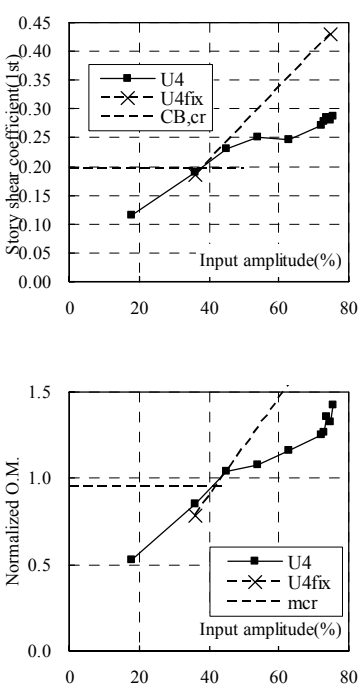

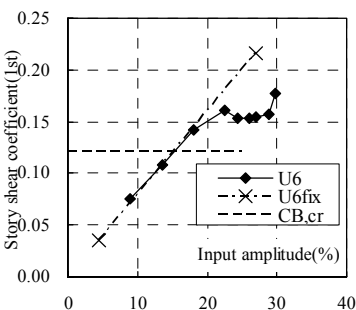

(a)
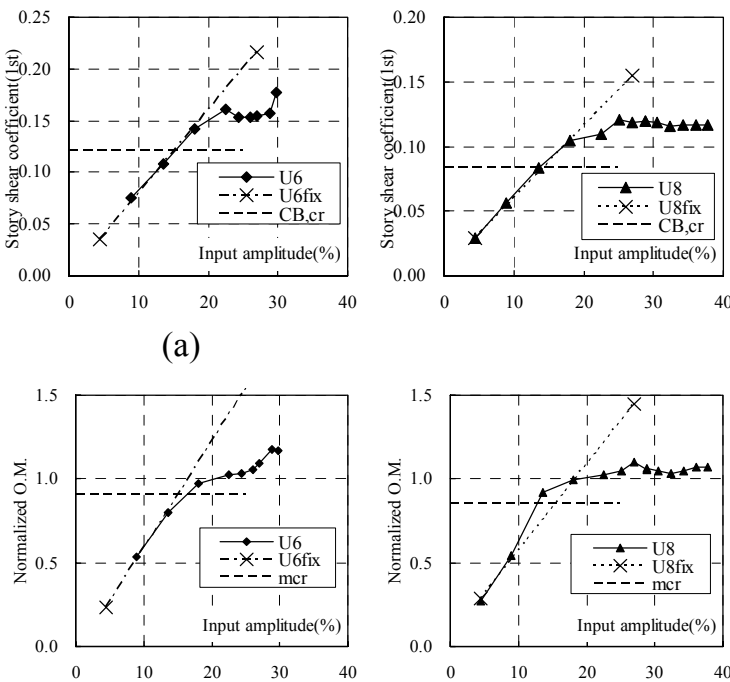

(b) 
Figure 7 summarizes the maximum displacements and accelerations. Uplift displacements are rapidly increased as the input amplitude increases. Roof horizontal displacements are also rapidly increased. Note that rigid rotations are dominant in roof displacements as mentioned above. Roof horizontal accelerations are almost as large as those of fixed base condition.

Figure 8 shows the maximum load displacement relationships. Doted lines show the stiffness of fixed base condition and critical values. U4 is subjected larger forces than U6 and U8 due to the smaller aspect ratio $H / B$. In the range of the tests, maximum responses reach about 1.5 times larger values than the corresponding critical ones.

Figure 9 shows the distribution of responses along the height. In the figure, "Ai" shows the distribution defined as standard one in building standard law in Japan. As pointed out in the analytical basic study [11], transient uplift motion changes the distribution of normalized story shear coefficient into top heavy one. Normalized horizontal accelerations are almost as large as or larger than those of fixed base condition. Secondary systems in the buildings allowed to uplift wound be affected by these relatively large acceleration. To evaluate the responses of secondary systems in uplifting buildings, further study is needed including the effect of shortening of vibration period mentioned above.
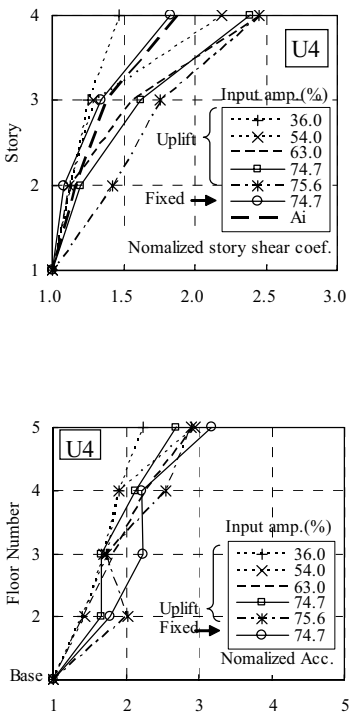
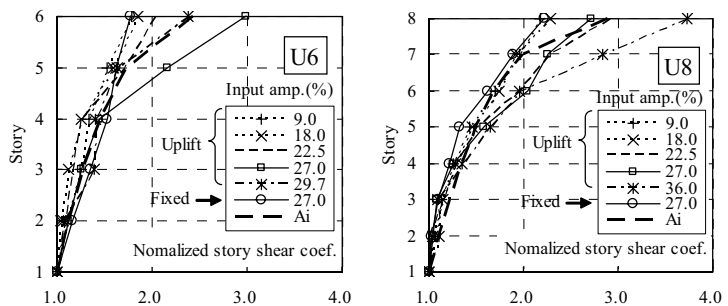

(a)
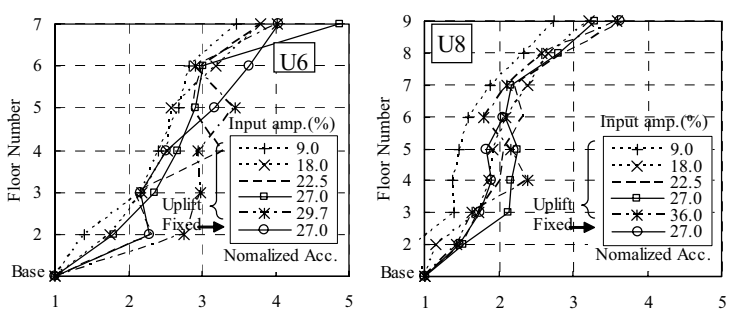

(b)

Figure 9: Normalized responses along the height: (a) normalized story shear coefficient; (b) normalized horizontal acceleration. 


\section{Conclusion}

In this paper, part of the results of parametric shaking table tests conducted with small scale shear type building models allowed to uplift are reported. Conclusions are summarized as follows:

1) Seismic response reduction effect is confirmed.

2) Once a transient uplift motion starts, shorter periodic vibrations are clearly observed in the tests. These phenomena can be recognized to be higher mode effect as pointed out in the literature.

3) Transient uplift motion changes the distribution of normalized story shear coefficient into top heavy one.

4) Normalized horizontal accelerations of floors are almost as large as or larger than those of fixed base condition.

\section{Acknowledgements}

Part of this work is supported by the National Research Institute for Earth Science and Disaster Prevention (NIED) of Japan and the Ministry of Education, Culture, Sports, Science and Technology (MEXT) of Japan under Grant-in-Aid for Scientific Research, Project No. 18560572 and 16360284. The supports are gratefully acknowledged.

\section{References}

[1] Rutenberg, A., Jennings, P.C., \& Housner, G.W., The response of veterans hospital building 41 in the San Fernando earth-quake. Earthquake Engineering and Structural Dynamics, 10, pp.359-379, 1982.

[2] Hayashi, Y., Tamura, K., Mori, M. \& Takahashi, I., Simulation analysis of buildings damaged in the 1995 Kobe, Japan, earthquake considering soilstructure interaction. Earthquake Engineering and Structural Dynamics, 28, pp.371-391, 1999.

[3] Muto, K., Umemura, H., \& Sonobe, Y., Study of the overturning vibration of slender structures. Proceedings of the Second World Conference on Earthquake Engineering, 2, pp.1239-1261, 1960.

[4] Meek, J.W., Effect of foundation tipping on dynamic response. Journal of Structural Engineering, 101(ST7), pp.1297-1311, 1975

[5] Meek, J.W., Dynamic response of tipping core buildings. Earthquake Engineering and Structural Dynamics, 6, pp.437-454, 1978.

[6] Yim, S.C-S. \& Chopra, A.K., Simplified earthquake analysis of multistory structures with foundation uplift, Journal of Structural Engineering, 111 (12), pp.2708-2731, 1985

[7] Oliveto, G., Calio, I., \& Greco, A., Large displacement behavior of a structural model with foundation uplift under impulsive and earthquake excitations. Earthquake Engineering and Structural Dynamics, 32, pp.369-393, 2003 
[8] ATC-40 Seismic evaluation and retrofit of concrete buildings, volume 2 Appendices, Appendix F: Supplemental information on foundation effects. Applied Technology Council, 1996.

[9] Midorikawa, M., Azuhata, T., Ishihara, T. Matsuba, Y. \& Matsushima, Y., Earthquake response reduction of buildings by rocking structural systems, Proceedings of SPIE, Smart structures and materials, pp.265-272, 2002.

[10] Midorikawa, M., Azuhata, T., Ishihara, T. \& Wada, A., Shaking Table Tests on Seismic Response of Steel Braced Frames with Column Uplift, Earthquake Engineering and Structural Dynamics, 35(14), pp.1767-1785, 2006

[11] Ishihara, T., Midorikawa, M. \& Azuhata, T., Vibration characteristics and dynamic behaviour of multiple story buildings allowed to uplift, Proceedings of SPIE, Smart structures and materials, 6169, pp.61691A-18, 2006 